\title{
A FAVELA BRASILEIRA SEXAGENÁRIA
}

\author{
Clovis Ultramari ${ }^{1}$, https://orcid.org/0000-0002-6441-3547, ultamari@yahoo.com \\ Marcelo Caetano Andreoli ${ }^{2}$, https://orcid.org/0000-0001-9270-3640, marcelocandreoli@gmail.com
}

1 Pontifícia Universidade Católica do Paraná, 80215-901, Curitiba - PR, Brasil

2 Universidade Federal do Paraná, 80060-000, Curitiba - PR, Brasil

Submitted: 31/07/2021. Accepted: 28/09/2021

Published: 29/09/2021

\begin{abstract}
RESUMO
Objetivo: O presente artigo destaca a importância do livro O Quarto de Despejo, de Carolina Maria de Jesus, para a compreensão profunda sobre a informalidade e os assentamentos populares de nossa cidade brasileira contemporânea. Metodologia: Esta obra é tomada como uma narrativa de testemunho e constituinte de um contexto ampliado e rico para pesquisas interdisciplinares. Embora escrito na década de 60, a escrita biográfica é atual, pois expõe a intensidade dos acontecimentos de uma vida marcada pela marginalidade e informalidade que pouco se alteraram ao longo da história nas cidades brasileiras. Resultados: Construir um olhar sobre a vulnerabilidade a partir do Quarto de Despejo é, sobretudo, uma busca pelo reposicionamento do urbanismo enquanto campo disciplinar que historicamente compreende o território pela centralidade da vida, reposicionando a ótica tecnicista, agora subordinada à sensibilidade do cotidiano. Contribuição para o conhecimento: o artigo reitera a validade do uso da literatura como fonte complementar para se entender a cidade, a importância do atributo interdisciplinar na compreensão do fenômeno urbano e o valor do enfoque qualitativo e pessoal para a compreensão de um objeto complexo.
\end{abstract}

PALAVRAS-CHAVE: carolina maria de jesus, informalidade, habitação social, favela, vulnerabilidade.

\section{THE BRAZILIAN SLUM TURNS 60}

\begin{abstract}
Purpose: This article reinforces the importance of Quarto de Despejo (Child of the Dark, in its English translation), by Maria Carolina de Jesus, to deeply understand the informality of illegal settlements in the contemporary Brazilian city. Metodology: This article is taken as a vivid testimony and as a part of larger context, thus rich for interdisciplinary researches. Although written in the 1960's, Carolina's autobiography is absolutely contemporary for exposing the intensity of an everyday life full of vulnerabilities: attributes still present among us nowadays. Findings: To take "Quarto de Despejo" as a possible true picture of real life is, more than anything else, a desire for repositioning urban planning as a science that has preferably taken the territory through the lens of central powers. Such required reposition reconsiders technical approaches and values sensibility and individuality. Contribution to knowledge: The article ends with a clear conviction that literature, as an additional source, is absolutely rich in our intention to understand cities, that it may help to exercise interdisciplinary urban analyses and that qualitative and individual approaches do add value to technical and general conclusions concerning the comprehension and management of a complex object.
\end{abstract}

KEYWORD: carolina maria de jesus, informality, social housing, favela, vulnerability. 


\section{A OBRA COMO UMA FONTE ADICIONAL}

Este artigo, curto, intenciona validar o livro de Carolina como fonte alternativa e complementar para se entender a cidade contemporânea, sobretudo as suas questões relativas à informalidade, acesso à terra urbana e à habitação social. Aqui, toma-se esse livro como relato de um mundo real, capaz de demonstrar as vivências marginais à cidade formal e de contribuir para entendermos como a favela mudou em 60 anos. ".. os poetas do lixo precisam lidar com um tipo de regressão social que os desafia, na medida em que estão sofrendo um processo de afastamento de suas bases culturais e materiais, que também é de exclusão das bases culturais e materiais da vida urbana, supostamente civilizada" (Bergamini, 2019, p. 10).

O interesse nesta obra justifica-se por dois contextos: um literário e outro da importância da interdisciplinaridade na compreensão da cidade. Proença Filho (2004) distingue na literatura brasileira os textos sobre o negro e os textos do negro. O livro Quarto de Despejo se insere na segunda tipologia, indo além, confirmando-se como literaturas-testemunho e constituindo uma tendência literária no Brasil: de uma hegemônica produção branca e masculina (Dalcastagnè, 2011), passamos a um cenário alvissareiro, confirmado, por exemplo, pela maior feira literária do país, onde, dos cinco livros mais vendidos, quatro eram de autores negros (Flip, 2019). O segundo contexto que justifica este interesse é a necessidade, há muito defendida, de se buscar fontes alternativas, complementares, interdisciplinares, para se entender a cidade. Ultramari e Jazar (2016) falam em "vazios investigativos" passíveis de serem ocupados pela literatura como fonte reveladora das camadas intangíveis do processo urbano.

As mesmas justificativas poderiam ser feitas para a obra de Conceição Evaristo, escrito na década de 1980 e lançado em 2006. Com esse tem-se um par de obras literárias capazes de revelar, sempre pela narrativa de quem vivencia um processo, a constituição de um compartimento urbano como a favela (como na obra de Carolina) e o cotidiano de insegurança vivenciado nesses tipos de compartimentos quando submetidos a ameaças de relocação forçada (como na obra de Conceição). Esses livros ganham importância aqui não pela perspectiva da crítica literária, mas como relatos sobre assentamentos informais da cidade brasileira, tornando-se, pois, singulares para o estudo do urbano. Ambos reposicionam o olhar do urbanismo de uma compreensão majoritariamente tecnicista ou legalista para uma vivência cotidiana relatada por sentimentos e histórias pessoais meio a um contexto urbano ampliado. Se tomados em conjunto, tais obras ofertam um relato dos momentos e fatos importantes para a compreensão da favela brasileira: 1. o da sua formação e seu cotidiano e 2. o da sua relocação, expulsão de moradores e surgimento de outros projetos urbanos.

A obra Quarto de Despejo completou 60 anos em 2020. Escrita por Carolina Maria de Jesus, moradora da Favela do Canindé, em São Paulo, sem o domínio da gramática e do léxico do português culto, transformou-se em leitura obrigatória para estudantes brasileiros e foi traduzida para várias línguas desde então. "Comecei a fazer meu diário ... Bateram na porta ... Era Seu João ... Quis saber o que eu escrevia. Eu disse ser o meu diário. Nunca vi uma preta gostar tanto de livros como você" [diz seu interlocutor] (p. 23). A descrição do cotidiano de uma favela do final dos anos 1950 numa metrópole brasileira que daí podem confirmar avanços, retrocessos e permanências na luta pela terra urbana de nosso país.

Esses mesmos procedimentos são encontrados na outra obra aqui apresentada, a de Conceição Evaristo, em Becos da Memória (2017), agora a partir de uma experiência passada e vivida; já como uma escritora que domina a língua culta. Assim, aquilo que Carolina teve a sorte de não ver, está revelado por Conceição: a insegurança frente a uma urbanização que eliminaria a Favela do Cruzeiro, na zona sul de Belo Horizonte, para dar lugar a um mercado municipal. A leitura desses dois livros revela atributos de um cotidiano de difícil apreensão em estudos e relatórios técnicos ou projetos urbanos. Depois de várias narrativas angustiantes que descrevem a ameaça constante de uma remoção, a fatalidade ocorre: "Os caminhões chegavam de manhã e até a tarde da noite levavam as famílias. Todos já estavam mesmo querendo partir. A vida tinha se 
tornado insuportável" (p. 166). Quase ao final do livro, a lembrança de uma subperiferização se faz presente: "A família de Maria Nova já tinha para onde ir. Logo que começou o desfavelamento, Maria Velha e Mãe Joana começaram a comprar um lote lá onde Deus tinha pensado iniciar o mundo. Era um lugar de matos e bichos. Bem calmo. Era longe" (p. 172). Na trajetória de vida de tio Totó, outro personagem, tem-se um percurso urbano que, mais uma vez, outorga empiria ao estudo do urbano brasileiro: morador pioneiro há 50 anos na favela do Cruzeiro, chegara da área rural, a pé, na cidade, com dinheiro para construir um barraco em terreno que não era - e jamais seria - seu. Trabalha como auxiliar de pedreiro, constrói sua casa no final de semana: "Quando cheguei na favela, ainda tinha muito lugar vazio. Essa minha casa era só um quartinho, fui aumentando aos poucos. Hoje, você vê, menina, são quatro cômodos" (p. 89). Outros relatos apresentados por Conceição, igualmente nos ajudam a compreender, confirmar e especificar temáticas recorrentes nos estudos urbanos da cidade brasileira: carência de infraestruturas em determinadas áreas, gentrificação, valorização diferenciada da terra urbana mesmo no interior da favela, distinção dessa dos bairros formais do entorno, proposição e implementação de "projetos estratégicos".

\section{METODOLOGIA}

Do mesmo modo que em Conceição, confirmando a atualidade dessas obras, ao final da obra de Carolina, temos uma indicação da permanência das coisas. Em O Quarto de Despejo, na virada da década, Carolina escreve: "Espero que 1960 seja melhor que 1959. Sofremos tanto no 1959, que dá para a gente dizer: Vai, vai mesmo! Eu não quero você mais. Nunca mais!”. Entretanto, mudanças não ocorrem; nas suas notas de 1 de janeiro de 1960, Carolina escreve: "Levantei as 5 horas e fui carregar água" (p. 213). Em Becos da Memória, já nos anos 2000, sob as promessas de uma nova legislação urbana federal, o Estatuto da Cidade (Brasil, 2001), Conceição, prestes a ser removida para dar lugar ao atual Mercado Cruzeiro, vê "Deus escondido atrás das nuvens", olhando impassível a fragilidade de todos. A água da torneira pública "caía pouco, lenta, preguiçosa, como se fosse um favor. Havia má vontade em tudo. Havia uma má vontade no viver” (p. 163).

Nem Carolina, nem Conceição conheceram em suas épocas de faveladas, sinais alvissareiros de mudanças; no sucesso de seus livros, pelas suas capacidades de incrementarem sensibilidades em relação aos nossos problemas urbanos, contribuem para entendermos o processo de favelização, desfavelização e mesmo de reurbanização. As duas autoras nos presenteiam com narrativas paradigmáticas sobre a favela brasileira e seus contextos. Com isso, confirmam a validade de se utilizar outras fontes de informação, complementares, para entendermos a cidade e para pensarmos modos de sua gestão. Junto aos seus leitores mais numerosos, contribuem para a difusão da crítica contundente em relação ao atual processo urbano brasileiro. Lidas em conjunto com outras obras literárias sugerem um rico ambiente de pesquisa, seja pela perspectiva histórica, seja pela construção de retratos contemporâneos.

A leitura da obra de Carolina, ou de outras que compõem um contexto muito maior, contribui, por último, para a construção dos chamados estudos urbanos críticos, receosos da visão tecnicista, constituída fundamentalmente em planos e zoneamentos. Tais estudos seriam mais bem embasados se pensados também com a ajuda de etnografias que revelem grandes processos sociais, conforme sugerido por Koster (2020). A informalidade do morar de Carolina e de Conceição coloca em dúvida os tais planos e leis; suas vidas particulares revelam temporalidades urbanas importantes para a compreensão da cidade brasileira. Suas narrativas literárias acompanham e reproduzem aquilo apresentado em estudos acadêmicos como, por exemplo: Valladares (2000), com uma revisão histórica das políticas urbanas em relação a favelas no Rio de Janeiro, Perlman (2010) em estudo com os moradores dos morros dessa mesma cidade e, exploratoriamente no recorte das cidades brasileiras, citam-se estudos de Andreoli e Moreira (2015), Magrini e Catalão (2017), Marostica (2017), Jesus e Denaldi (2018), e Ferreira (2019). Sempre, nesses casos, a constatação de 
como intervenções urbanas são eventos pessoais relevantes, impondo temporalidades e histórias pessoais.

\section{A FAVELA BRASILEIRA SEXAGENÁRIA}

A leitura dessas obras é também obrigatória para pesquisadores de questões urbanas contemporâneas, seja por revelar um cotidiano pretérito em áreas informais de nossas cidades, seja por sugerir mudanças e permanências na luta pela terra urbana em nossas cidades. "Estou residindo na favela. Mas se Deus me ajudar hei de mudar daqui. Espero que os políticos estingue as favelas" (p. 17). "Fui no rio lavar as roupas .... Estendi as roupas rapidamente e fui catar papel. Que suplício catar papel atualmente! Suporto o peso do saco na cabeça e suporto o peso de Vera Eunice [sua filha] nos braços" (p. 19). "Se eu pudesse mudar desta favela! Tenho a impressão que estou no inferno" (p 24).

A precariedade da vida revelada por Carolina Maria de Jesus denuncia a favela como espaço à margem da cidade, carente de infraestrutura, desiludida em relação aos políticos, familiarizada com o subemprego e sempre ameaçada por projetos de reurbanização. Embora em alguns momentos a autora apresente otimismo em relação ao contexto político, na maior parte do livro a desesperança e a invisibilidade constroem a relação com a política institucional, reafirmando a carência de políticas públicas e de ações concretas na favela onde mora.

A narrativa em formato de diário expõe, dia após dia, carências vividas no seu espaço urbano e moradia, e contrastes ainda hoje muito conhecidos nas nossas cidades: "Eu classifico São Paulo assim: O Palacio, é a sala de visita. A Prefeitura é a sala de jantar e a cidade é o jardim. E a favela é o quintal onde jogam os lixos" (p. 31). "O que posso esperar do futuro? .... As dificuldades corta o afeto do povo pelos políticos" (p. 32). "Credo, para viver num lugar assim, só os porcos. Isto aqui é o chiqueiro de São Paulo" (p. 34).

A vinculação entre autora e espaço permite debater o conceito de direito à cidade: a sua vulnerabilidade demonstra dinâmicas urbanas e espacialidades da pobreza para além da precariedade infraestrutural. De fato, a construção das subjetividades nestes contextos é frontalmente afetada pela vulnerabilidade física e social, condicionando a existência das pessoas da favela do Canindé a uma possível ilegalidade existencial, conforme afirmaria Boaventura Sousa Santos (2010).

Admitir tal condição amplia conceitos sobre as cidades e inclui aspectos sensíveis da vida. As passagens recorrentes em que a fome é protagonista reafirmam uma condição urbana restrita ao ganho imediato de dinheiro para subsistência, aproximando determinados grupos de uma relação servil e subalterna na metrópole. "E assim, no dia 13 de maio de 1958 [em referência à de libertação dos escravos no Brasil, em 1888) eu lutava contra a escravatura atual - a fome!” (p. 29).

No circuito urbano desenvolvido pela autora do diário, observa-se uma clara relação espacial entre o local de moradia (a favela), os pontos de produção e de venda de reciclados (seu papel catado) e locais de possível ajuda (sedes de governo e de filantropia social). Uma mobilidade extremamente restrita em uma metrópole que já contava com quase quatro milhões de habitantes (Ibge, Censo de 1960). A especialização dos locais referenciados por Carolina demonstra essa restrição geográfica que certamente reflete um cotidiano carente de coisas e de relações sociais. 


\section{Quadro 1: Mobilidade da autora na cidade de São Paulo}

\begin{tabular}{|c|c|}
\hline Referência geográfica encontrada na obra & Categoria espacial \\
\hline $\begin{array}{l}\text { Virei na Frei Antonio Galvão*. Quase não tinha papel .... enchi dois } \\
\text { sacos na rua Alfredo Maia (1) ... (p. 22). }\end{array}$ & Trabalho \\
\hline Fui na feira da Rua Carlos de Campos (2), catar qualquer coisa (p. 26). & Trabalho \\
\hline $\begin{array}{l}\text { Era [sic] } 11 \text { horas quando eu recordei do convite do tenente da } 12 \\
\text { Delegacia (3) (p. 26). }\end{array}$ & Locais de possível ajuda \\
\hline $\begin{array}{l}\text { Estão construindo um circo aqui na Rua Araguaia (4), Circo Theatro } \\
\text { Nilo (p. 27). }\end{array}$ & Moradia \\
\hline $\begin{array}{l}\text { Quando eu seguia a Avenida Cruzeiro do Sul (5) ia uma senhora com } \\
\text { um saco azul ... (p. 34). }\end{array}$ & Trabalho \\
\hline $\begin{array}{l}\text { Fui falar com a policia feminina que me deu a notícia que José Carlos } \\
\text { estava lá na Rua Asdrúbal Nascimento (6) (p. 35). }\end{array}$ & Locais de possível ajuda \\
\hline $\begin{array}{l}\text { O Julião é revoltado, mas sem motivo. Ele não precisa residir na favela. } \\
\text { Tem casa no Alto de Vila Maria (7) (p. 37). }\end{array}$ & Moradia \\
\hline Estava na favela**, na lama, nas margens do Tietê (p. 39). & Moradia \\
\hline $\begin{array}{l}\text { Pus a carne com uns tomates que eu catei lá na Fabrica [sic] Peixe* (p. } \\
41) \text {. }\end{array}$ & Moradia / Trabalho \\
\hline $\begin{array}{l}\text { O senhor mandou-me ir na [sic] Avenida Brigadeiro Luis Antonio (8), } \\
\text { eu fui. Avenida Brigadeiro mandou-me ir na Santa Casa (9). E eu gastei } \\
\text { o único [sic] dinheiro que eu tinha com as conduções (p. } 43 \text { ). }\end{array}$ & Trabalho \\
\hline $\begin{array}{l}\text {... na Avenida Cruzeiro do Sul } 728 \text { (10) uma senhora pediu-me para eu ir } \\
\text { jogar um cachorro morto dentro do Tietê que dava-me } 6 \text { cruzeiros (p. } \\
\text { 49). }\end{array}$ & Trabalho \\
\hline Na Avenida do Estado 1140 (11) ganhei muito papel (p. 63). & Trabalho \\
\hline $\begin{array}{l}\text { Li o cartão. Era para ir buscar um premio e uma surpresa para seu filho } \\
\text { na rua Javaés } 771(12) \text { (p. 73). }\end{array}$ & Locais de possível ajuda \\
\hline $\begin{array}{l}\text { A preta disse-me que era empregada de Dona Mara, que dança na Boite } \\
\text { Oasis na rua } 7 \text { de Abril (13)... deu-me este endereço: Avenida São João, } \\
19082 \text { andar apartamento } 23 \text { (14). O que deixou-me preocupada foi o } \\
\text { prédio ter } 82 \text { andar (p. 86). }\end{array}$ & Trabalho \\
\hline $\begin{array}{l}\text { José Carlos chegou. Vou trocá-lo para ir na Casa Gouveia* comprar um } \\
\text { par de sapatos (p. 94). Descrição de inúmeros momentos de pequenas } \\
\text { compras junto a pequenos comércios no Canindé. }\end{array}$ & Comércio / Moradia \\
\hline $\begin{array}{l}\text { Aqui na favela do Canindé**, há } 160 \text { casos positivos de doença } \\
\text { caramujo (p. 111). }\end{array}$ & Moradia \\
\hline $\begin{array}{l}\text { Passei numa casa da Avenida Tiradentes (15) e levei } 50 \text { quilos papel } \\
\text { que uma senhora deu-me para vender para ela (p. 119). }\end{array}$ & Trabalho \\
\hline $\begin{array}{l}\text { As } 5 \text { horas comecei vestir-me para eu ir no Centro Espírita Divino } \\
\text { Mestre* receber os donativos natalinos (p. 160). }\end{array}$ & Locais de possível ajuda \\
\hline
\end{tabular}

Fonte: Autores, baseado em Carolina Maria de Jesus, 2014.

* Lugares cuja espacialização é demasiadamente imprecisa.

** Favela do Canindé, demarcada no mapa pelo polígono pontilhado. 
A figura 1 espacializa os percursos do quadro 1 e confirma uma geografia limitada da autora, majoritariamente a pé.

\section{Figura 1: Os percursos a pé relatados por Maria Carolina de Jesus}

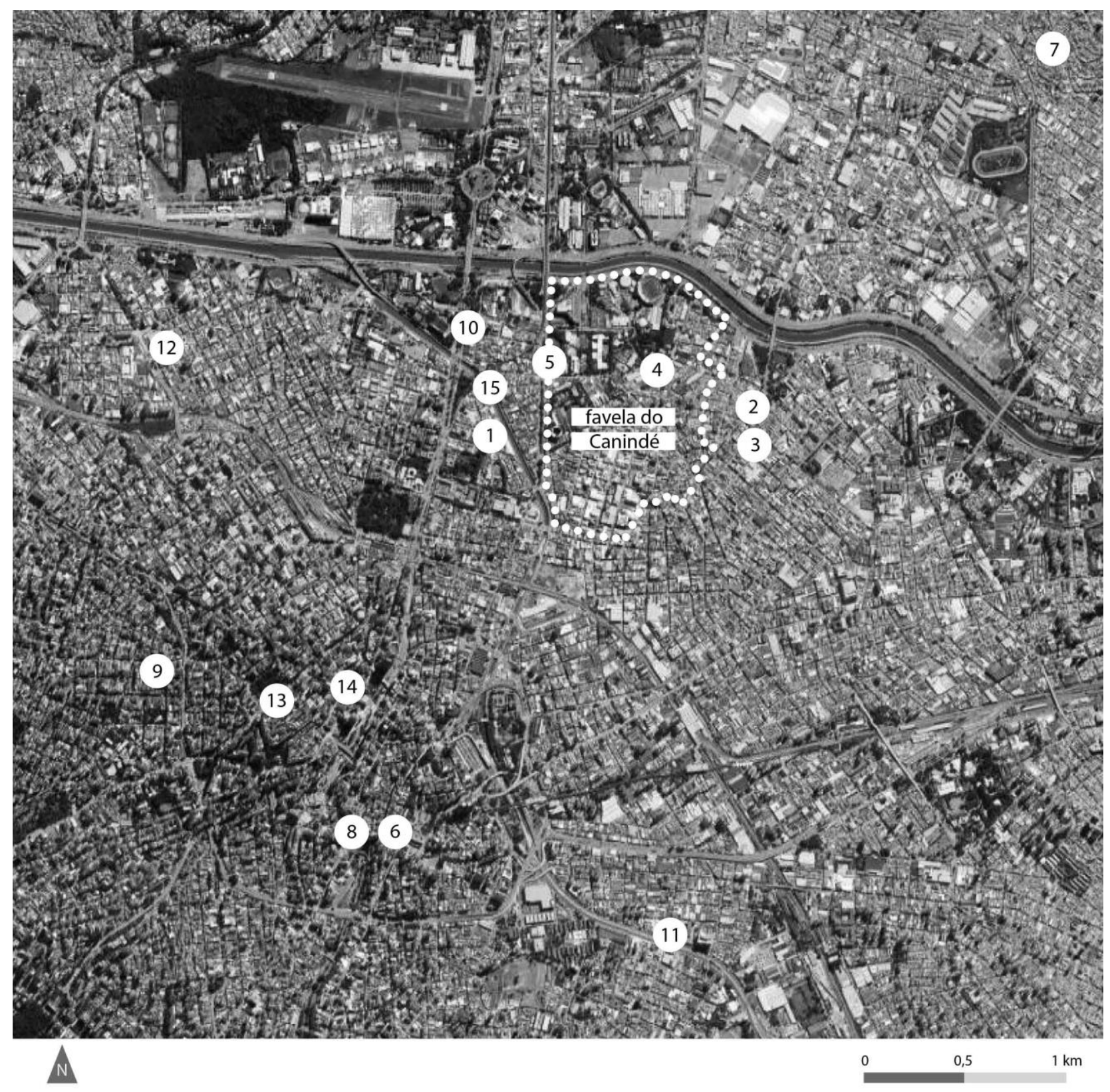

Fonte: Autoria própria, 2021.

O trabalho de Carolina Maria de Jesus como catadora de papel representava uma atividade ainda incipiente na cidade brasileira no final da década de 1950. A despeito deste serviço já ocorrer no início do século XX, é só a partir dos anos 1990 que ele se impõe em termos significativos de número de pessoas envolvidas (de uma falta de dados para os anos 1960, hoje seriam prováveis 400 mil catadores, segundo CEM, 2016), do volume coletado (chegando à $90 \%$ do reciclável no país, segundo IPEA, 2010) e presença na cidade, prováveis 400 mil em 2004, segundo Dagnino e Johansen (2017).

Diferentemente do trabalho relatado por Carolina, a qual relata um carregar de materiais em saco de 30kg, o catador de hoje, nas ruas de São Paulo, em sua quase totalidade, serve-se de 
carrinhos ou carroças e carrega em média $500 \mathrm{~kg}$, podendo chegar até $800 \mathrm{~kg}$ (Besen, 2011). Também em relação à extensão do trajeto do catador contemporâneo: de seus possíveis nas ruas de São Paulo, 60 anos depois, têm-se menções a mais de 10km/dia, conforme descrição das principais cooperativas de lixo reciclável com atuação nesta cidade.

O contexto da favela do Canindé, local de moradia de Carolina Maria de Jesus, é o de uma São Paulo que conhecera suas primeiras favelas nos anos 1940, com a conhecida (vide a Favela do Oratório, na zona leste e a da Rua Guaicurus, na zona central, segundo Pasternak Taschner (2001). Tal surgimento seria muito posterior ao de outra grande cidade do país, Rio de Janeiro, com confirmações desse tipo de ocupação já nos primeiros anos de 1900 (Valladares, 2000). Passados os 60 anos da obra de Carolina, o número de favelados em São Paulo, reconhecidamente, amplia-se no território, metropoliza-se, complexifica-se, diversifica-se diante das pressões do interesse imobiliário ou de projetos urbanísticos da gestão urbana. De um total aproximado de 60 mil favelados no final da década de 1950 em São Paulo (São Paulo, 1962), esse número chegaria hoje a cerca de 2 milhões (Ibge, 2010).

A favela do Canindé, na margem do rio Tietê, com aproximadamente 35 mil m2 e 300 domicílios, à época de Carolina, não mais existe. "Não era fácil viver no Canindé, todo ano as águas do Tietê invadiam uma parte dos barracos, obrigando os moradores a procurarem as áreas mais altas, mudando-se temporariamente. Quando o rio baixava, eles voltavam para dar início à reconstrução e resgatar o que ainda pudesse ser aproveitado" (Peres, 2007).

A ida de Carolina para essa favela, em 1948, teria como origem os processos de higienização do governo Adhemar de Barros, que obrigaria moradores de cortiço a viver em terrenos vulneráveis nas margens do Tietê (Mitsuuchi, 2015). Na virada de 1960 para 1961, em um momento não mais relatado na obra em questão, e como resultado das fortes chuvas, a favela é demolida ao longo de doze meses e sua população distribuída por 75 bairros de São Paulo (Peres, 2007). Os procedimentos para o fim da favela do Canindé, segundo o Plano de Desfavelamento da Cidade de São Paulo (São Paulo, 1962), incluíam: viagem para a cidade ou estado de origem, mudança para quarto ou casa alugada, mudança para casa adquirida, mudança para construção de madeira construída pela periferia (em terreno próprio favelado ou em terreno municipal, mudança para construção de madeira ou alvenaria, efetuada pelo próprio favelado, e compra de material para construção em terreno de propriedade do favelado (apud França, 2009).

No caso de Carolina, a mudança ocorre para um sítio, em Parelheiros, $40 \mathrm{~km}$ de seu antigo barraco (Barone, 2015). O fim da sua favela não é relatado por Carolina em seu livro; tarefa literária que parece ter deixado para Conceição Evaristo fazer em seu Becos da Memória, Está aí descrito aquilo que Carolina não viu: o agonizante processo de insegurança dos moradores frente a uma urbanização que eliminaria a Favela do Cruzeiro, na zona sul de Belo Horizonte, para dar lugar a um mercado municipal. A leitura desses dois livros revela atributos de um cotidiano de difícil apreensão em relatórios técnicos ou projetos urbanos. O contexto deles é o de uma valorização atual da literatura nacional com conhecimento in situ da realidade da qual se quer falar, uma fonte potencial para o estudo sobre a questão habitacional brasileira. Nem Carolina, nem Conceição, conheceram em suas épocas de faveladas, sinais alvissareiros de mudanças; no sucesso de seus livros, pelas suas capacidades de incrementarem sensibilidades em relação aos nossos problemas urbanos, é que poderiam visualizar a gênese de um possível novo momento urbano.

Nas últimas páginas de O Quarto de Despejo, a esperança por mudanças é seguida pela contundente permanência das coisas: "Espero que 1960 seja melhor que 1959. Sofremos tanto no 1959, que dá para a gente dizer: Vai, vai mesmo! Eu não quero você mais. Nunca mais!" Todavia, as mudanças parecem não acontecer. Nas suas notas de $1^{\circ}$ de janeiro de 1960 , entretanto, ela escreveria: "Levantei as 5 horas e fui carregar água" (p. 213). De fato, permanecem ou se ampliam as desilusões em relação a governos, com destinatário ainda não esclarecido, mas com detalhes claros, pragmáticos de demandas. "Juscelino esfola! Janio Mata! Adhemar rouba! A Câmara apoia! E o povo sofre! (p. 34). 


\section{CONSIDERAÇÕES FINAIS}

Carolina Maria de Jesus, assim como Conceição Evaristo e outras e outros que poderiam ser agregados a esse tipo de fonte que se buscou discutir aqui, compõem um cenário paradigmático das narrativas sobre as favelas; em seus livros, as tensões e contradições da cidade são expostas a partir de um relato biográfico e personificado. Suas narrativas literárias contribuem para que se reorientem perspectivas do urbanismo, demonstrando a urgência para uma prática sensível, que reconheça os corpos e os atravessamentos constitutivos que sustentam os territórios.

Perceber os lugares e suas dinâmicas é sobretudo uma disputa pela vida diante da técnica, reafirmando estes livros como peças literárias fundamentais para a compreensão da vida nas cidades. Não foi a intenção neste artigo arriscar análises literárias; ao contrário, propositadamente, afastamo-nos desse intuito todo o tempo.

A valorosa alternativa de uma narrativa negra feita por negros e negras é estrategicamente aqui valorizada como figuração para dizermos outra coisa. É valioso alternar e complementar o tecnicismo na gestão e no entendimento urbanos pela especificidade dos indivíduos que compõe a realidade sabidamente diversa que existe nas cidades. Também não falamos da contundência dos perfis dos personagens descritos por Carolina - e por Conceição -, capazes de convencer o leitor. Propositadamente, nos satisfez confirmar a atualidade de seus relatos na construção e apropriação da cidade brasileira.

\section{REFERÊNCIAS}

Andreoli, M., \& Moreira, T. (2015). Uma análise histórico conceitual dos megaeventos esportivos e seus desdobramentos na cidade contemporânea. EURE (Santiago), 41(123), 289-307. https://doi.org/10.4067/S025071612015000300012

Barone, A. C. C. (2015). ST 10 CAROLINA MARIA DE JESUS, UMA TRAJETÓRIA URBANA. Anais ENANPUR, 16(1).

Bergamini, A. (2020). Dar forma ao impublicável: Carolina Maria de Jesus e sua arte. Estudos de Literatura Brasileira Contemporânea, 59, e595, 1-13. https://doi.org/10.1590/2316-4018595

Besen, G. R. (2011). Coleta seletiva com inclusão de catadores: construção participativa de indicadores e índices de sustentabilidade. Tese (Doutorado em Saúde Pública) - Faculdade de Saúde Pública, Universidade de São Paulo, São Paulo.

Brasil, O. (2001). Estatuto da cidade-Lei Federal no. 10.257.

Cem, Centro de Estudos da Metrópole (2016). Censo 2010: bases de dados do projeto Censo. São Paulo, CEM/USP. Disponível em: https://goo.gl/3Kvyel. Acesso em: 15 jan 2021.

Dagnino, R. D. S., \& Johansen, I. C. (2017). Os catadores no Brasil: características demográficas e socioeconômicas dos coletores de material reciclável, classificadores de resíduos e varredores a partir do Censo Demográfico de 2010. In: Relatórios IPEA, economia solidária e políticas públicas, 62. Brasília: Abr 2017, p. 115 - 125.

Dalcastagnè, R. (2011). A personagem do romance brasileiro contemporâneo: 1990-2004. Estudos de Literatura Brasileira Contemporânea, (26), 13-71. Recuperado de https://periodicos.unb.br/index.php/estudos/article/view/9077 Acesso em: 15 junho 2021.

Evaristo, C. (2017). Becos da Memória. Rio de Janeiro: Pallas Editora.

Ferreira, F. (2019). Irregularidade da posse da terra urbana, invasão de domicílios e espaço metropolitano. EURE (Santiago), 45(136), 93-111. https://doi.org/10.4067/S0250-71612019000300093

Flip. 17 a edição da Flip (Festa Literária Internacional de Paraty). Flip 2019: Dos 5 autores mais vendidos, 4 são negros e 1 é indígena. In Jornal Vermelho. Disponível em https://vermelho.org.br/prosa-poesia-arte/flip-2019-dos-5-autoresmais-vendidos-4-sao-negros-e-1-e-indigena/ Acesso em: 15 junho 2021. 
França, E. (2009). Favelas em São Paulo (1980-2008). Dos projetos de desfavelamento aos projetos de urbanizaçao. A experiencia do Programa Guarapiranga. Tese (Doutorado em Arquitetura e Urbanismo) - Universidade Mackenzie, Faculdade de Arquitetura e Urbanismo, São Paulo.

Ibge. Censos Demográficos. Disponível em www.ibge.gov.br. Acesso em: 20 jan 2020.

Ipea, Instituto de Pesquisa Econômica Aplicada (2010). Pesquisa sobre pagamento por serviços ambientais urbanos para gestão de resíduos sólidos. Brasília: Ipea.

Jesus, M. C. (2014). Quarto de Despejo: diário de uma favelada. Editora São Paulo: Ática.

Jesus, P., \& Denaldi, R. (2018). Experiências de regulação urbana e suas possibilidades: análise a partir do Programa Minha Casa Minha Vida na Região do Grande abc (São Paulo). EURE (Santiago), 44(132), $67-87$. https://doi.org/10.4067/s0250-71612018000200067

Koster, M. (2020). An ethnographic perspective on urban planning in Brazil: Temporality, diversity and critical urban theory. International journal of urban and regional research, 44(2), 185-199. https://doi.org/10.1111/1468-2427.12765

Magrini, M. A., \& Catalão, I. (2017). Del derecho al consumo al derecho a la ciudad: contradicciones y convergencias. EURE (Santiago), 43(130), 25-46. https://doi.org/10.4067/s0250-71612017000300025

Marostica, L. (2017). Reestructuración de la metrópoli periférica y el impasse de la reforma urbana en Curitiba. Revista EURE-Revista de Estudios Urbano Regionales, 43(128). https://doi.org/10.4067/S0250-71612017000100012

Mitsuuchi, J. T. A. (2018). Contextos, reflexões e análises: Carolina Maria de Jesus e o Quarto de Despejo. Revista Vernáculo, (41). https://doi.org/10.5380/rv.v0i41.50466

Pasternak Taschner, S. (2001). Favelas em São Paulo - censos, consensos e contra-censos. In: Cadernos Metrópole, 5, 9-27. https://doi.org/10.4067/S0250-71612001008000005

Peres, E. P. (2007). Exuberância e invisibilidade: populações moventes e cultura em São Paulo, 1942 ao início dos anos 70. Tese (Doutorado em História Social) - Universidade de São Paulo, Faculdade de Filosofia, Letras e Ciências Humanas, São Paulo.

Perlman, J. (2010) Favela: four decades of living on the edge in Rio de Janeiro. Oxford University Press. Oxford.

Proença Filho, D. (2004). A trajetória do negro na literatura brasileira. Estudos avançados, 18, 161-193. https://doi.org/10.1590/S0103-40142004000100017

Santos, B. S.; Meneses, M. P. (2010). Epistemologias do Sul. São Paulo: Editora Cortez.

São Paulo (1962). Desfavelamento do Canindé. Divisão do Serviço Social da PMSP.

Ultramari, C., \& Jazar, M. M. (2016). LITERATURA E CIDADE: campo interdisciplinar e vazios investigativos. Cadernos de Pesquisa, 23(2), 107-121. http://dx.doi.org/10.18764/2178-2229.v23n2p107-121

Valladares, L. (2000). A gênese da favela carioca. A produção anterior às ciências sociais. Revista brasileira de ciências sociais, 15, 05-34. https://doi.org/10.1590/S0102-69092000000300001 


\section{DECLARATION OF CONTRIBUTIONS TO THE ARTICLE - CRediT}

\begin{tabular}{|c|c|c|}
\hline ROLE & CUltramari & MAndreoli \\
\hline $\begin{array}{l}\text { Conceptualization - Ideas; formulation or evolution of overarching research goals and } \\
\text { aims. }\end{array}$ & $\mathrm{x}$ & \\
\hline $\begin{array}{l}\text { Data curation - Management activities to annotate (produce metadata), scrub data and } \\
\text { maintain research data (including software code, where it is necessary for interpreting } \\
\text { the data itself) for initial use and later re-use. }\end{array}$ & $\mathrm{x}$ & \\
\hline $\begin{array}{l}\text { Formal analysis - Application of statistical, mathematical, computational, or other } \\
\text { formal techniques to analyze or synthesize study data. }\end{array}$ & & $\mathrm{x}$ \\
\hline $\begin{array}{l}\text { Funding acquisition - Acquisition of the financial support for the project leading to } \\
\text { this publication. }\end{array}$ & - & - \\
\hline $\begin{array}{l}\text { Investigation - Conducting a research and investigation process, specifically } \\
\text { performing the experiments, or data/evidence collection. }\end{array}$ & $\mathrm{x}$ & \\
\hline Methodology - Development or design of methodology; creation of models. & $\mathrm{x}$ & \\
\hline $\begin{array}{l}\text { Project administration - Management and coordination responsibility for the research } \\
\text { activity planning and execution. }\end{array}$ & $\mathrm{x}$ & \\
\hline $\begin{array}{l}\text { Resources - Provision of study materials, reagents, materials, patients, laboratory } \\
\text { samples, animals, instrumentation, computing resources, or other analysis tools. }\end{array}$ & - & - \\
\hline $\begin{array}{l}\text { Software - Programming, software development; designing computer programs; } \\
\text { implementation of the computer code and supporting algorithms; testing of existing } \\
\text { code components. }\end{array}$ & - & - \\
\hline $\begin{array}{l}\text { Supervision - Oversight and leadership responsibility for the research activity } \\
\text { planning and execution, including mentorship external to the core team. }\end{array}$ & $\mathrm{x}$ & \\
\hline $\begin{array}{l}\text { Validation - Verification, whether as a part of the activity or separate, of the overall } \\
\text { replication/reproducibility of results/experiments and other research outputs. }\end{array}$ & & $\mathrm{x}$ \\
\hline $\begin{array}{l}\text { Visualization - Preparation, creation and/or presentation of the published work, } \\
\text { specifically visualization/data presentation. }\end{array}$ & & $\mathrm{x}$ \\
\hline $\begin{array}{l}\text { Writing - original draft - Preparation, creation and/or presentation of the published } \\
\text { work, specifically writing the initial draft (including substantive translation). }\end{array}$ & $\mathrm{x}$ & $\mathrm{x}$ \\
\hline $\begin{array}{l}\text { Writing - review \& editing - Preparation, creation and/or presentation of the } \\
\text { published work by those from the original research group, specifically critical review, } \\
\text { commentary or revision - including pre- or post-publication stages. }\end{array}$ & $\mathrm{x}$ & $\mathrm{x}$ \\
\hline
\end{tabular}

